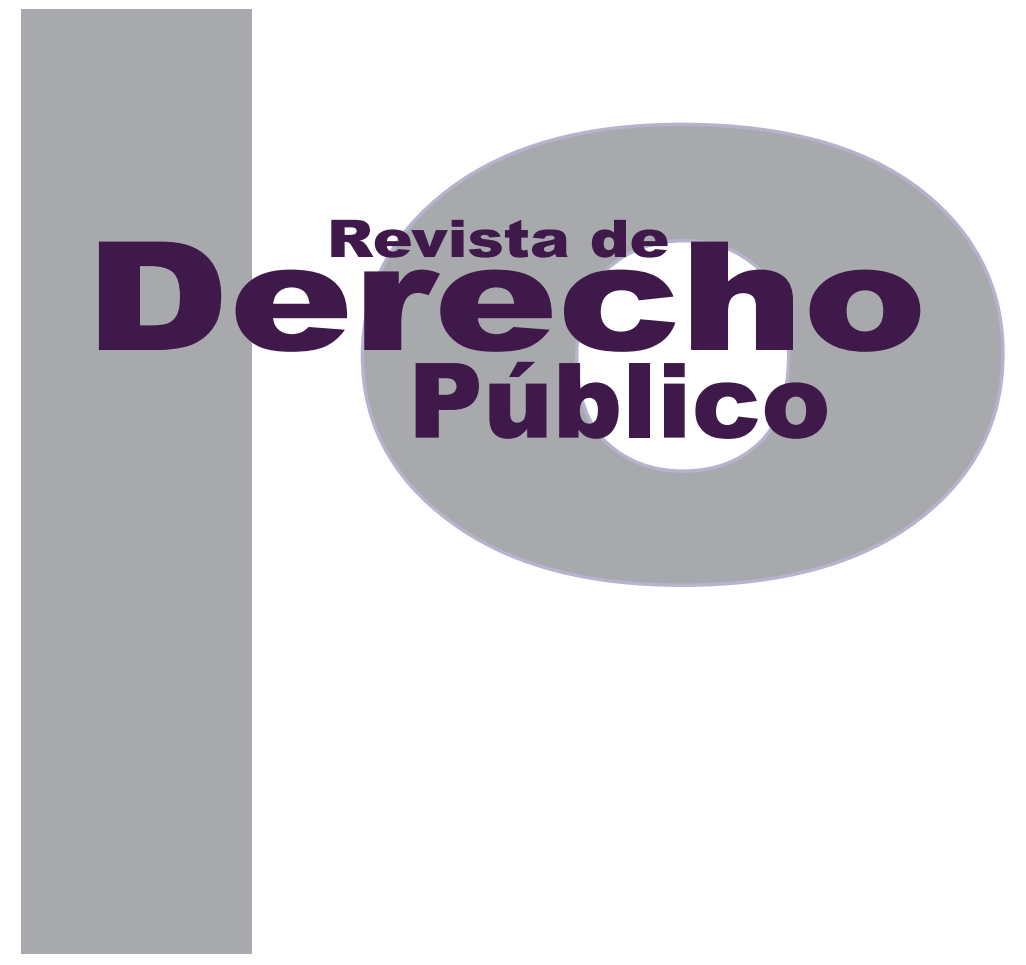

\title{
¿POR QUÉ LOS JUECES NO APRUEBAN LAS CONCILIACIONES ADMINISTRATIVAS? GARANTISMO JUDICIAL Y DEFICIENTE GESTIÓN PROCESAL DE LAS ENTIDADES
}

\author{
Paula María Vargas García \\ Artículo de reflexión \\ DOI: http://dx.doi.org/10.15425/redepub.34.2015.18 \\ Universidad de los Andes \\ Facultad de Derecho \\ Revista de Derecho Público N. ${ }^{\circ} 34$ \\ Enero - Junio de 2015. ISSN 1909-7778
}




\title{
¿Por qué los jueces no aprueban las conciliaciones administrativas? Garantismo judicial y deficiente gestión procesal de las entidades
}

\section{Resumen}

Este estudio se hizo como parte de una investigación adelantada por la Agencia Nacional de Defensa Jurídica del Estado, en la que se analizó la totalidad de los autos mediante los cuales los magistrados de la sección tercera del Tribunal Administrativo de Cundinamarca y de la sección tercera del Consejo de Estado improbaron los acuerdos conciliatorios presentados por distintas entidades del orden nacional durante los años 2010 a 2014, con el fin de entender cuáles son las principales causales por las que hoy los jueces imprueban las conciliaciones. Se pudo concluir que, en su gran mayoría, estas causales están relacionadas con fallas en la gestión judicial de las entidades o con posturas excesivamente garantistas de los jueces frente a algunos temas. Dilucidar estas causales permitió establecer algunos lineamientos básicos para reducir la posibilidad de que se imprueben las conciliaciones administrativas.

Palabras clave: conciliación administrativa, autos improbatorios, causales de improbación, análisis empírico del derecho, derecho administrativo.

\section{$¿$ Why do judges reject conciliations between the State and the people? Paternalism and a deficient procedural management}

\begin{abstract}
This study was elaborated by the National Agency for the Legal Defense of the State as part of a research meant to analyze all judicial decisions rendered by the highest courts for administrative matters, in which conciliation agreements between the State and civil parts were denied during the period from 2010 through 2014. This allowed the Agency to understand the main causes as to why judges deny the agreements. In conclusion, most causes are related with a deficient judicial management within the State entities or with paternalist postures from the judiciary. Identifying this causes allowed the Agency to issue a series of recommendations in order to decrease the range of administrative recommendations denied by the highest courts.
\end{abstract}

Keywords: conciliation between the State and the people, rejection rulings, empirical analysis of the law, administrative law, causes of rejection.

\section{Por que os juízes não aprovam as conciliações administrativas? Garantismo judicial e deficiente gestão processual das entidades}

\section{Resumo}

Este estudo foi feito como parte de uma pesquisa realizada pela Agência Nacional de Defesa Jurídica do Estado, na que foi analisada a totalidade dos autos mediante os quais os magistrados da seção terceira do Tribunal Administrativo de Cundinamarca e da seção terceira do Conselho de Estado improbaram os acordos conciliatórios apresentados por distintas entidades de ordem nacional durante os anos 2010 a 2014, com o fim de entender quais são as principais causais pelas quais hoje os juízes improbam as conciliações. Foi possível concluir que, em sua grande maioria, estas causais estão relacionadas com falhas na gestão judicial das entidades ou com posturas excessivamente garantistas dos juízes frente a alguns temas. Dilucidar estas causais permitiu estabelecer alguns lineamentos básicos para reduzir a possibilidade de que se improvem as conciliações administrativas.

Palavras-chave: conciliação administrativa, autos improbatórios, causais de improbação, análises empírico do direito, direito administrativo. 


\title{
¿Por qué los jueces no aprueban las conciliaciones administrativas? Garantismo judicial y deficiente gestión procesal de las entidades*
}

\author{
Paula María Vargas García**
}

\section{SUMARIO}

Introducción - I. DIAGNÓSTICO DESCRIPTIVO DE LOS AUTOS IMPROBATORIOS - II. CAUSALES DE IMPROBACIÓN DE LA CONCILIACIÓN - A. Frecuencia con la que se presentan las causas de improbación de la conciliación - B. Descripción de las causas por las que se imprueba la conciliación - 1. Causales de improbación que comparten las conciliaciones judiciales y extrajudiciales - 2. Causales de improbación propias de la conciliación judicial - 3. Causales de improbación propias de la conciliación extrajudicial - III. RECOMENDACIONES - A. Recomendaciones a la gestión de las entidades B. Recomendaciones para los jueces administrativos - IV. CONCLUSIONES - Referencias.

Cómo citar este artículo: Vargas García, P. M. (Junio, 2015). ¿Por qué los jueces no aprueban las conciliaciones administrativas? Garantismo judicial y deficiente gestión procesal de las entidades. Revista de Derecho Público, 34. Universidad de los Andes (Colombia).

** Abogada de la Universidad de los Andes. Especialista en Responsabilidad y Daño Resarcible de la Universidad Externado de Colombia. Abogada litigante en asuntos administrativos en las firmas Cremades \& Calvo Sotelo y Prieto \& Carrizosa S. A. Actualmente, contratista de la Agencia Nacional de Defensa Jurídica del Estado (ANDJE). Correo: paula.vargas@defensajuridica.gov.co

Agradezco a Alejandro Peláez, experto de la ANDJE, su apoyo en la revisión del artículo. 
Introducción

El propósito de este estudio es analizar los autos improbatorios proferidos por las instancias judiciales de mayor jerarquía en la jurisdicción contencioso administrativa, con el fin de comprender las causales por las que se han improbado las conciliaciones presentadas por las entidades del Estado durante el periodo comprendido entre el 2010 y el 2014. Su relevancia radica en que a partir de este diagnóstico es posible emitir recomendaciones a los jueces y a las entidades del Estado con el fin de reducir el número de conciliaciones administrativas que se frustran y que terminan siendo parte de los casos que congestionan la justicia.

El estudio se hizo con base en sesenta autos improbatorios de conciliaciones proferidos durante el periodo 2010-2014. Estos se obtuvieron de las secretarías de las distintas secciones del Consejo de Estado y del Tribunal Administrativo de Cundinamarca, y corresponden al universo total de autos para dicho periodo en el Consejo de Estado y una muestra significativa para el caso del Tribunal Administrativo de Cundinamarca.

Luego de conseguir las referencias de los procesos se obtuvo copia física de cada uno de los autos y con ellos se estructuró una base de datos que contiene toda la información relevante, que más adelante permitió hacer un diagnóstico.

A partir de este diagnóstico se pudo concluir que la improbación de las conciliaciones está relacionada con fallas que recaen no solo en la gestión judicial de las entidades, sino también en posturas paternalistas de los jueces. En esta medida, las recomendaciones que se emitieron estuvieron encaminadas a superar estos dos aspectos.

El desarrollo de este documento comienza con un diagnóstico cuantitativo descriptivo de los autos, en donde se especifica, entre otros, cuáles son los casos en los que los jueces suelen improbar las conciliaciones. A continuación se hace una descripción cualitativa de las causales por las que se imprueba la conciliación, discriminando entre aquellas que comparten la conciliación judicial y extrajudicial, aquellas que son propias de la conciliación judicial y aquellas de la conciliación extrajudicial. Posteriormente, se establecen recomendaciones tanto para jueces, como para las entidades del Estado. Finalmente, se exponen las conclusiones.

\section{DIAGNÓSTICO DESCRIPTIVO DE LOS AUTOS IMPROBATORIOS}

De los autos obtenidos, el $78 \%$ fueron emitidos por el Consejo de Estado y el 22\% por el Tribunal Administrativo de Cundinamarca. 
Ilustración 1. Autos improbatorios por tipo de tribunal.

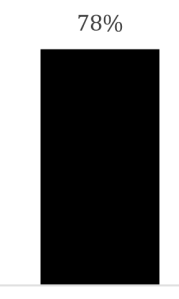

Consejo de Estado

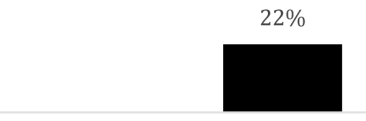

Tribunal Adm. Cundin.

De los autos improbatorios que se profirieron en el curso de un proceso, el Consejo de Estado emitió el $98 \%$. En el caso de los autos improbatorios proferidos extrajudicialmente, el Tribunal Administrativo de Cundinamarca profirió el $71 \%$.

Las conciliaciones que se improbaron, independientemente de si eran judiciales o extrajudiciales, surgieron todas a propósito de hechos que darían lugar a acciones de reparación directa o de controversias contractuales. El $74 \%$ iniciaban como consecuencia de una acción de reparación directa, y el $26 \%$ como consecuencia de una acción de controversias contractuales.

llustración 2. Autos improbatorios por tipo de acción.

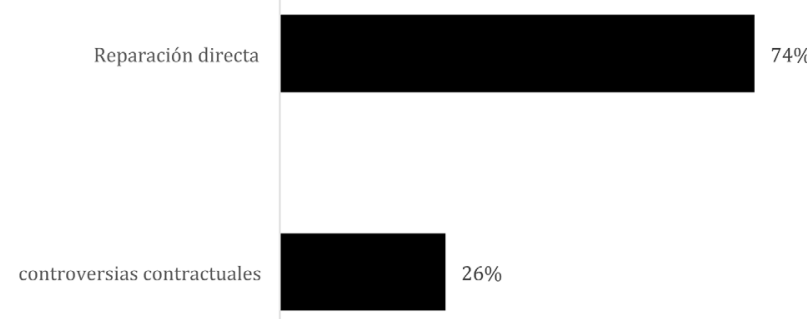

Se consideró importante establecer las causales propias de cada una de estas acciones, con el fin de determinar si ante ciertas circunstancias el Consejo de Estado o el Tribunal Administrativo de Cundinamarca tienen tendencia a no aprobar las conciliaciones que presentan las entidades del Estado.
Las conciliaciones improbadas como consecuencia de acciones de controversias contractuales se relacionan, en el $73 \%$ de los casos, con el incumplimiento de obligaciones contractuales por parte de la entidad.

llustración 3. Causal que generó la controversiacontractual.

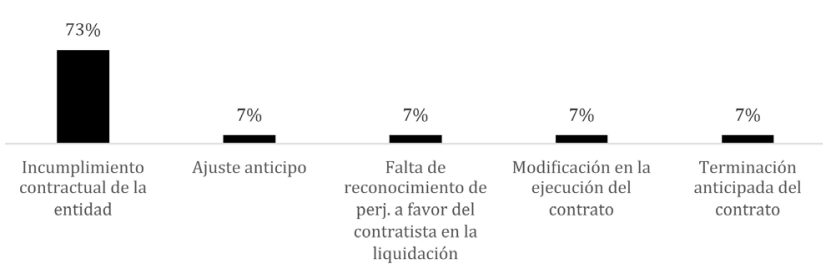

En la acción de reparación directa la causa más frecuente es la privación injusta de la libertad (35\%), seguida por acto terrorista (19\%) y falla médica (14\%. Las causales que menos se presentan son: accidente de tránsito, allanamiento ilegal y secuestro, con el $3 \%$.

Ilustración 4. Causal de la acción de controversiascontractuales

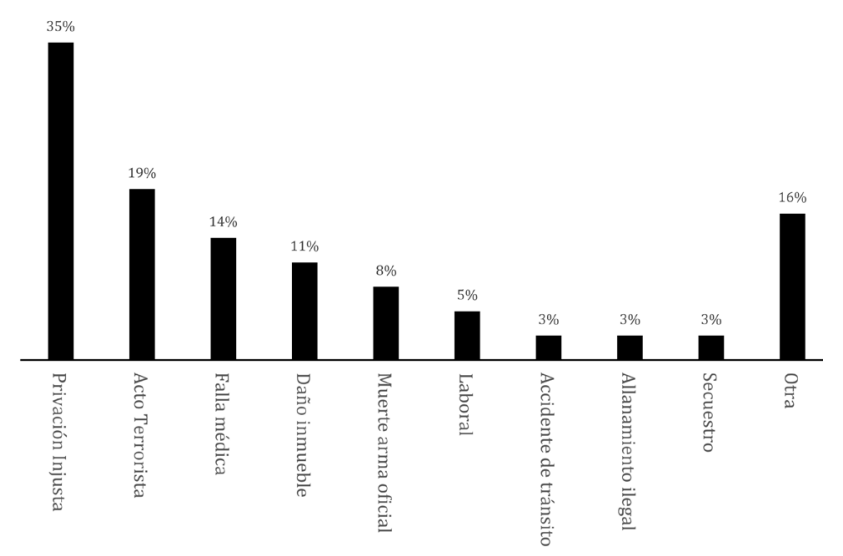

También resultaba relevante establecer si las solicitudes de conciliación improbadas judicialmente estaban precedidas por una sentencia previa que favoreciera a alguna de las partes. Lo anterior, en la medida en que, como se mostrará más adelante, la causal principal por la que 
se improbaron las conciliaciones es la falta de pruebas suficientes para justificar la legalidad de la conciliación.

En el $98 \%$ de los casos que daban origen a los autos de improbación de conciliaciones judiciales, y en el $100 \%$ de los casos de privación injusta de la libertad, de falla médica y de daño a inmueble, ya existía una sentencia de primera instancia que favorecía siempre a los particulares.

Era también importante establecer qué ocurría en el tiempo con aquellas conciliaciones que resultaban improbadas, con el fin de determinar si en la continuación del litigio había una mayor tendencia a que las entidades resultaran ganadoras o si por el contrario estas perdían. Tal información resultaba útil para confirmar a quiénes perjudica en mayor medida que la conciliación no se lleve a su fin.

Con el fin de extraer estos datos se recurrió a la información más importante de cada uno de los procesos, para luego poder rastrearlos en el sistema virtual de la rama judicial. La mayor dificultad para hacer el diagnóstico estuvo en que por ser todos autos muy recientes, muchos de los litigios que le dieron continuación a la controversia que se intentaba dirimir con la conciliación aún siguen en curso.

En el caso de las improbaciones judiciales el $48 \%$ de los procesos todavía siguen en curso. El fallo del proceso en el $35 \%$ fue a favor de los particulares y solo en el $10 \%$ a favor del Estado.
Ilustración 5. Continuidad del proceso - conciliaciónjudicial.

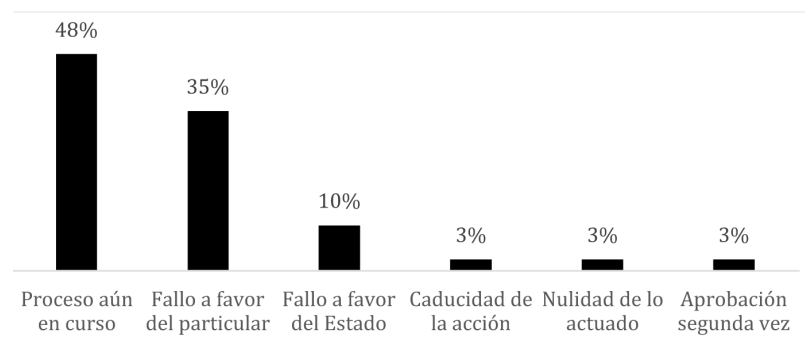

Era especialmente importante determinar el porcentaje de casos que en primera instancia fueron desfavorables al Estado, y que por esta misma razón la entidad intentó conciliar para luego obtener una sentencia favorable a sus pretensiones en segunda instancia. Este dato permitió establecer que, específicamente, en el $25 \%$ de los casos revisados la sentencia de segunda instancia resultó favorable para la entidad; en el otro $75 \%$ la entidad acertó al procurar conciliar el caso antes de proferirse la sentencia de segunda instancia.

\section{CAUSALES DE IMPROBACIÓN DE LA CONCILIACIÓN}

Con el fin de explicar estas causales, primero se enunciará la frecuencia con la que se presentan en la conciliación extrajudicial y judicial. Luego se analizará con más detalle cada una de dichas causales.

\section{A. Frecuencia con la que se presentan las causas de improbación de la conciliación}

Dentro de las causales por las que se improbó la conciliación extrajudicial durante el periodo 
2010-2014, la principal, con una gran ventaja, es la falta de pruebas (58\%). A continuación están las causales de caducidad de la acción, la aprobación parcial y la interposición incorrecta de la acción, con una frecuencia del $8 \%$. Finalmente, están la falta de capacidad para conciliar, la falta de legitimidad en la causa, la ilegalidad del acuerdo y la lesividad del acuerdo, con el $4 \%$.

Ilustración 6. Frecuencia de las causales de improbación en la conciliación extrajudicial.

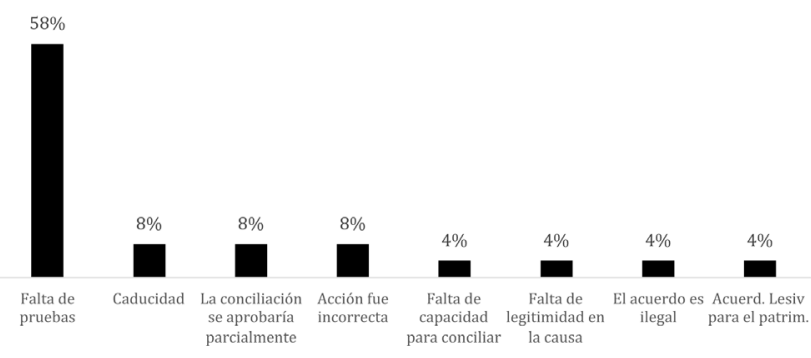

Las causales que se presentan en las conciliaciones judiciales son de naturaleza más variada. La de mayor frecuencia es, de nuevo, la falta de material probatorio, con el 35\%. A continuación, con una frecuencia del 14\% están la lesividad al patrimonio público y la presentación parcial de la conciliación. Las causales con menos frecuencia ( $2 \%$ ) son el desconocimiento del precedente jurisprudencial, que el acuerdo no verse sobre derechos económicos y la ilegalidad del acuerdo. llustración 7. Frecuencia de las causales de improbación en la conciliación judicial.

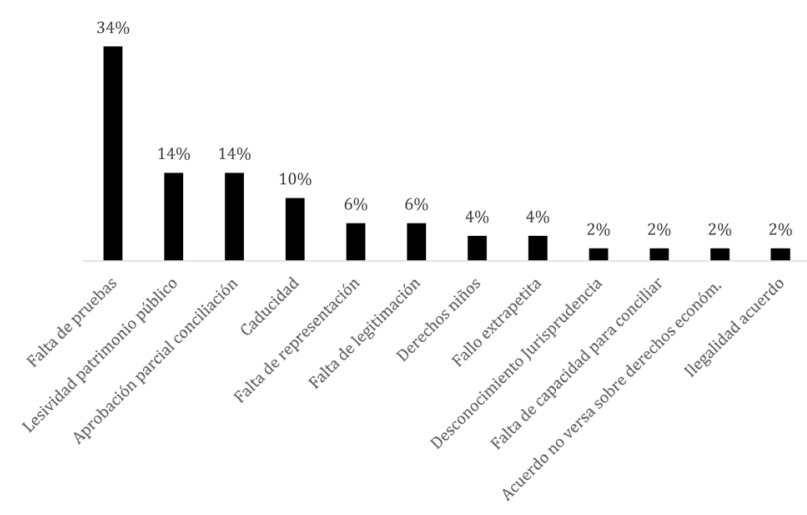

\section{B. Descripción de las causas por las que se imprueba la conciliación}

Para una mayor profundidad respecto a cada una de las causales, se analizarán primero aquellas que se encuentran en los autos de improbación judicial y extrajudicial, posteriormente solo las que se encuentran en la conciliación extrajudicial y finalmente las que solo se encuentran en la conciliación judicial.

\section{Causales de improbación que comparten las conciliaciones judiciales y extrajudiciales}

a) Falta de pruebas

La causal falta de pruebas consiste en que, a juicio de los magistrados, el acervo probatorio aportado por el particular y la entidad del Estado no tiene la capacidad de demostrar algún elemento de la responsabilidad de la entidad. En esta medida, si no existe certeza, aprobar el acuerdo conciliatorio puede implicar un detrimento injustificado a los recursos del Estado. 
El Consejo de Estado es quien en mayor medida imprueba conciliaciones por esta causal (56\% del total de los casos), mientras que el Tribunal Administrativo de Cundinamarca registró el 44\%.

En la gran mayoría de casos, esta causa de improbación no aparece ampliamente desarrollada en los autos revisados. Para alegar esta causal, los magistrados enuncian las pruebas aportadas al proceso y con base en ellas finalmente llegan a la conclusión de que estas no son suficientes para demostrar el daño causado por la entidad o la cuantía específica del daño. Sin embargo, es una constante que los magistrados no presentan mayor argumentación en cuanto a la razón por la que consideran que las pruebas no cumplen su propósito de probar que la conciliación se justifica.

Un ejemplo que ilustra esta circunstancia se puede encontrar en las sentencias proferidas por el Consejo de Estado en el 2012 (CE, Tercera, 5 jul. 2012, H. Andrade, Rad.: 2001684) y en el 2013 (CE, Tercera, 12 feb. 213, H. Andrade, Rad.: 34976) en las que primero se enlistan las pruebas aportadas con la solicitud de conciliación y luego se afirma:

Revisado el proceso, se encuentra que el presente acuerdo cumple con los requisitos señalados en los numerales 1, 2 y 3 de la presente providencia, sin embargo, no es posible sostener lo mismo respecto de lo dispuesto en el numeral 4 (Que el acuerdo conciliatorio cuente con las pruebas necesarias), pues la conciliación en materia contencioso administrativa y su posterior aprobación, por estar en juego el patrimonio estatal y el patrimonio público, una y otra deben estar respaldados con elementos probatorios idóneos y suficientes respecto del derecho objeto de controversia, de manera que no quede al Juez de conocimiento que existen altas probabilidades de condena en contra de la administración y que la aprobación del acuerdo conciliatorio resulta provechosa para los intereses de las partes en conflicto y en este evento no se observan (CE, Tercera, 12 feb. 213, H. Andrade, Rad.: 34976).

Este párrafo, recurrente en los autos improbatorios por falta de pruebas, es genérico y no le permite a las partes comprender frente a qué aspecto de la responsabilidad hubo una deficiencia probatoria.

En otros casos, el Consejo de Estado y el Tribunal Administrativo de Cundinamarca establecen brevemente el motivo por el que consideran que las pruebas no fueron suficientes para demostrar algún elemento de la responsabilidad. En estos es común que alguno de los hechos del proceso no haya sido demostrado mediante la formalidad que exige la Ley.

Un auto que ilustra esta circunstancia es el proferido por el Consejo de Estado el 6 de diciembre de 2010 (CE, Tercera, O. Valle de la Hoz, Rad.: 33462), en el que el juez de primera instancia afirma: "Para acreditar la condición de dueños del inmueble por el cual reclaman, los demandantes aportaron con la demanda copia del folio de matrícula inmobiliaria correspondientes al inmueble".

El Consejo de Estado considera que esta afirmación es desatinada, pues la formalidad para 
demostrar la propiedad de un inmueble es la escritura pública que constituye el título legítimo del contrato de la compraventa:

Al romper salta la duda para la Sala, el verdadero alcance que tuvo el a quo al hacer la valoración de la prueba existente en el proceso. Es evidente, y ello no admite discusión que, nuestra legislación habla de ciertas formas externas documentales necesarias para la prueba de algunos actos jurídicos o contratos y las llama solemnidades (...) Ejemplo de prueba solemne, que siempre se cita por lo frecuente, es la compraventa que verse sobre derecho en un bien inmueble, "caso en el cual la escritura pública es, al propio tiempo que solemnidad, única prueba del contrato" y la única manera de acreditar el derecho de dominio de un inmueble es a través de la escritura pública (título) y su registro en la Oficina de Instrumentos Públicos (modo), si ello no ocurre así, la prueba no es idónea para acreditar el derecho de dominio que se invoca, prueba que brilla por su ausencia dentro del expediente (CE, Tercera, 6 dic. 2010, O. Valle de la Hoz, Rad.: 33462).

A partir de este razonamiento, el Consejo de Estado imprueba la solicitud de conciliación afirmando que no se puede tener certeza real de la propiedad del bien que fue presuntamente destruido por una negligencia del Estado.

Ahora, en la conciliación judicial la causal de falta de pruebas se aplica de manera especialmente estricta, pues las pruebas que acompañan la conciliación usualmente son las mismas que se anexan a las demandas y las contestaciones que presentan los particulares y las entidades en el litigio. Estas pruebas han sido previamente analizadas por el comité de conciliación de la entidad, quien para este punto ya ha determinado la conveniencia de hacer uso del mecanismo alternativo de solución de conflictos.

Sobre la causal de falta de pruebas vale la pena mencionar que son repetidas las ocasiones en las que se considera que no hay pruebas suficientes del daño generado por la entidad del Estado, aun cuando existe una sentencia previa en donde se probaron los hechos.

Específicamente, en el $47 \%$ de los casos que se imprueban por falta de pruebas ya ha existido un proceso previo, en el que se ha surtido la etapa probatoria, el cual ha finalizado con una sentencia en contra de la entidad.

\section{b. El acuerdo es lesivo para el patrimonio público}

Que un acuerdo sea lesivo para el patrimonio público implica que, a partir de una conciliación suscrita por una entidad pública y un particular, se va a incurrir en un gasto injustificado de recursos del Estado.

En todos los casos esta causal estaba acompañada de otra causal principal que al generarse, conllevaba que el acuerdo se volviera lesivo para el patrimonio.

Así por ejemplo, es reiterado en las conciliaciones judiciales y extrajudiciales el que se establezca que un acuerdo es lesivo para el patrimonio público porque las pruebas que se aportan en la conciliación no son suficientes para demostrar el daño o su cuantía. 
El auto del Consejo de Estado del 27 de junio de 2012 ilustra esta circunstancia. Este auto imprueba un acuerdo conciliatorio judicial porque no había certeza de que la privación de la libertad del particular hubiese sido injusta, por lo que no necesariamente iba a haber una condena en contra del Estado.

Literalmente, el Consejo de Estado establece:

El hecho de que se hubiere absuelto al señor Usme Cediel en virtud del principio in dubio pro reo, no implica, per se, que los demandantes tengan derecho a una indemnización por parte del Estado.

$(\ldots)$

Así las cosas, la Sala estima que aprobar el acuerdo conciliatorio puede resultar lesivo del patrimonio público y, por contera, violatorio del principio de legalidad (CE, Tercera. 27 jun. 2012, C. A. Zambrano, Rad.: 40634).

En el caso específico de la conciliación judicial también es reiterativo que se establezca que una conciliación es lesiva para el patrimonio, en la medida en que esta se estructure a partir de una sentencia de primera instancia que concede a los demandantes más de lo que solicitaron en sus pretensiones.

El auto del 14 de abril de 2011 proferido por el Consejo de Estado refleja esta circunstancia:

Sobre el particular en el acuerdo conciliatorio las partes pactaron que la Fiscalía General de la Nación pagaría el $100 \%$ del perjuicio a la vida en relación. Sin embargo, este último perjuicio no fue incluido en las pretensiones de la demanda.

De allí que se imponga la improbación del acuerdo conciliatorio puesto que la condena por perjuicios inmateriales, en la forma en que se hizo por el Tribunal de Primera Instancia resulta contradictorio y violatorio del principio de congruencia, pues, excedió a lo solicitado en el petitum de la demanda y por ende el convenio es lesivo para el patrimonio público" (CE, Tercera, 14 abr. 2011, E. Gil, Rad.: 38575).

Finalmente, el Consejo de Estado estableció que existía un acuerdo lesivo para el patrimonio cuando en el acuerdo conciliatorio judicial se incluían personas que no hacían parte del proceso (CE, Tercera, 24 abr. 2014, H. Andrade, Rad.: 24324).

\section{c. El acuerdo solo se aprobaría parcialmente}

De acuerdo con lo establecido por el Consejo de Estado y el Tribunal Administrativo de Cundinamarca, tanto las conciliaciones judiciales como las extrajudiciales deben ser aprobadas de manera exacta a como las partes las acordaron.

Esto implica que el juez administrativo debe improbar la totalidad del pacto en caso de encontrar que al menos una de sus cláusulas no se ajusta a los requisitos exigidos para este mecanismo de solución de conflictos.

Así, si alguna de las causales de improbación aplica al menos a una de las cláusulas del acuerdo conciliatorio, la totalidad del acuerdo se debe improbar. 
Por ejemplo, en auto del 23 de mayo de 2012 d. Caducidad de la acción

el Consejo de Estado improbó la totalidad de un acuerdo conciliatorio porque no se probó en debida forma la filiación de una de las personas que se verían favorecidas con la conciliación:

Estima la Sala que no existe fundamento suficiente para aprobar la conciliación lograda entre las partes, (...) comoquiera que el juez al momento de realizar el examen de legalidad de las conciliaciones no puede impartir aprobaciones parciales respecto de las mismas en cuanto a que supone una invasión en la órbita de la autonomía de la voluntad que únicamente le corresponde definir a las partes (CE, Tercera, 23 may. 2012, M. Fajardo, Rad.: 31722).

Por su parte, en el auto del 4 de julio de 2012 el Consejo de Estado cita un auto de esta misma Corte que se reitera en distintas ocasiones y que establece:

En cuanto concierne con la posibilidad de efectuar aprobaciones parciales, la Sala ha sido enfática en señalar que la conciliación, si bien puede comprender la decisión sobre varias pretensiones que podrían analizarse de manera individual o autónoma, lo cierto es que la misma constituye un "universo único", es decir un acuerdo de voluntades genérico, sobre el cual debe restringir su estudio a la legalidad (CE, Tercera, 25 jul. 2007, R. Hoyos, Rad.: 29273B).

La justificación del Consejo de Estado y del Tribunal para no admitir la aprobación parcial de los acuerdos conciliatorios judiciales y extrajudiciales es que hacerlo implicaría alterar la voluntad de las partes que pretendieron conciliar totalmente la controversia.

Si la entidad pública busca conciliar, ya sea judicial o extrajudicialmente, un caso frente al cual ya ha operado la caducidad o la prescripción de la acción a favor del Estado, el juez administrativo debe improbarla por causar un detrimento injustificado a los recursos públicos.

Esta causal no es ampliamente desarrollada en Ios autos proferidos por el Tribunal Administrativo de Cundinamarca ni por el Consejo de Estado, pues en su análisis los magistrados citan la norma jurídica que establece el término de vigencia de la acción que haya dado origen a la conciliación para después determinar si esta se instauró antes o después de que operara la prescripción o la caducidad.

Esta circunstancia se ilustra bien en el auto del Consejo de Estado del $1^{\text {ro }}$ de noviembre de 2012 (CE, Tercera, 1 nov. 2012, E. Gil, Rad.: 40588). En este caso, una persona que presumiblemente fue privada injustamente de su libertad pretende que se le indemnice por todos los daños que esta situación le ocasionó. El proceso penal por el que se le condenó culminó el 28 de junio de 2004 y la acción en contra del Estado la instaura el 28 de agosto del 2008. Así, por cuanto la acción de reparación directa prescribe a los dos años de ocurridos los hechos (CA, art. 1368; CPACA, art. 164), el Consejo de Estado imprueba la conciliación.

\section{e. Falta de legitimación en la causa por activa}

El Consejo de Estado ha definido la legitimidad por activa como la posibilidad de formular las 
pretensiones de una demanda en tanto exista una relación directa con el objeto de la controversia. De manera literal esta Alta Corte ha establecido:

La legitimación en la causa hace referencia a la posibilidad de que la persona formule o controvierta las pretensiones de la demanda, por ser el sujeto activo o pasivo de la relación jurídica sustancial debatida en el proceso. Como se observa, las personas con legitimación en la causa, se encuentran en relación directa con la pretensión, ya sea desde la parte activa, como demandante, o desde la pasiva, como demandado (CE, Tercera, 24 oct. 2013, E. Gil, Rad.: 25869).

En esta medida, la causal de falta de legitimidad por activa consiste en que la persona que le dio origen a la solicitud de conciliación judicial o extrajudicial no tiene una relación directa con la controversia. Por esto mismo, este sujeto nunca tuvo la facultad de hacer parte de la polémica jurídica a través de la demanda o de la solicitud de conciliación, para la conciliación extrajudicial.

Un ejemplo que ilustra este caso se puede ver en el auto proferido por el Consejo de Estado el 29 de mayo de 2013. En esta providencia, se improbó el acuerdo conciliatorio porque se consideró que un menor no tiene legitimidad en la causa para solicitar que se le indemnice por los perjuicios inmateriales que le haya podido ocasionar la privación injusta de la libertad de su padre, pues al ocurrir este hecho dañoso el menor aún no había nacido:

Así entonces, no puede presumirse con la simple acreditación del parentesco que el deman- dante sufrió un daño moral consistente en el dolor ocasionado por encontrarse lejos de su padre (...) como quiera que no existe una regla de la experiencia que permita suponer que quien aún no ha nacido al momento dentro del periodo en el que se encontró privado de la libertad la víctima directa, sufre alguno de los perjuicios relacionados con anterioridad (CE, Tercera, 29 may. 2013, D. Rojas, Rad.: 25869).

Establece entonces el Consejo de Estado que, tratándose de perjuicios inmateriales, estos no se les pueden reconocer a los parientes por el solo hecho de estar relacionados, si no hay pruebas de que efectivamente se haya sufrido el daño.

\section{f) El acuerdo conciliatorio es ilegal}

Con el fin de que una conciliación pueda ser aprobada por el juez administrativo, es necesario que esta no sea celebrada en contravía de las normas jurídicas establecidas en nuestro ordenamiento jurídico. En esta medida, una conciliación debe ser improbada si, por ejemplo, es evidente que existen actos de corrupción, si el acuerdo implica obligaciones que sean contrarias a los pronunciamientos del Consejo de Estado o si se violan u omiten disposiciones de la Constitución, leyes de cualquier naturaleza o decretos expedidos por la autoridad administrativa.

Un ejemplo de esta causa se puede observar en el auto proferido por el Tribunal Administrativo de Cundinamarca el 11 de abril del 2012, con ponencia del magistrado C. Vargas, Rad.: 20111425. 
En este caso, una empresa particular siguió prestando a la Alcaldía Mayor de Bogotá unos equipos médicos necesarios para el funcionamiento de las unidades de cuidados intensivos de los recién nacidos, luego de haber concluido el contrato formal de arrendamiento de las máquinas, con el fin de no afectar el funcionamiento normal de la IPS y la vida de los pacientes.

Ante esta circunstancia, la Alcaldía Mayor de Bogotá y la empresa particular suscribieron la conciliación con el fin de que esta entidad del Estado le pagara al particular los cánones de arrendamiento adeudados.

Esta situación la encuentra ilegal el Tribunal Administrativo de Cundinamarca, por contrariar las normas de contratación administrativa en cuanto a los requisitos formales que debe tener cualquier contrato estatal o sus respectivas prórrogas.

Literalmente el Tribunal afirma:

Si bien el servicio prestado sin respaldo contractual por la entidad convocante obedeció al arrendamiento de equipos biomédicos para las ucl, tal aspecto no reviste de urgencia evidente que conlleve al desconocimiento de la normatividad contractual vigente, pues a juicio del despacho, para mitigar los efectos de la terminación del contrato de arrendamiento anterior que recaía sobre dichos equipos, pudieron haberse adoptado otras alternativas diferentes a la evasiva en la aplicación del régimen de contratación.

\section{(...)}

Debe advertirse en este punto que el desconocimiento del estatuto de contratación no debe obedecer al capricho o negligencia de las personas que están legítimamente habilitadas para intervenir en las relaciones contractuales con el Estado (...) y por ello es evidente el apartamiento no razonado ni justificado de las normas que rigen el actuar contractual de la administración (TAC, Tercera, 11 abr. 2011, C. Vargas, Rad.: 2011-1425).

Arguye entonces el Tribunal que los hechos del caso no reúnen los requisitos para que se entienda que existió un enriquecimiento sin causa por parte de la entidad que justifique la erogación del gasto público. Por el contrario, considera que el acuerdo conciliatorio violó las normas de contratación estatal por haber sido desconocidas por las partes al momento de prorrogar el contrato de arrendamiento.

\section{g) Falta de capacidad para conciliar}

Esta causal se presenta cuando algún sujeto de la conciliación pretende pactar sobre ciertos derechos que no son de su esfera de disposición. Esto puede ocurrir porque la persona a quien pertenecen los derechos no ha brindado la debida autorización para que otro disponga de ellos o porque los derechos que se pretenden conciliar son irrenunciables.

En esta medida, cuando las partes incurren en esta causal de improbación están omitiendo uno de los requisitos fundamentales de la conciliación; solamente se pueden conciliar aquellos derechos que pertenecen a la órbita de disposición de la persona.

Un ejemplo de improbación por esta causa está en el auto del 1 de agosto de 2012, donde el 
Consejo de Estado imprueba la conciliación propuesta por las partes porque en la sentencia proferida en primera instancia se otorgaron una serie de daños inmateriales a favor de un menor de edad, que más adelante se desconocen en el acuerdo conciliatorio. En este acuerdo, los mayores de edad solo pactan el reconocimiento de daños materiales a favor de personas distintas al niño. En el mencionado auto el Consejo de Estado concretamente establece:

Es así que la renuncia a la condena por daños morales proferida a favor de Johan Santiago López Piedrahita, sin importar que hubiere sido manifestada por sus representantes legales por medio de apoderado debidamente constituido para el efecto, resulta inaceptable en tanto compromete la satisfacción de derechos que por su naturaleza son irrenunciables.

$(\ldots)$

En este orden de ideas, el despacho improbará el acuerdo conciliatorio al que llegaron las partes el 12 de abril del 2012, en consideración a que se trata de los derechos de un menor de edad de 15 años que estuvo expuesto a una situación especial de violencia, de tal forma que garantizarán sus derechos y se hará prevalecer sobre los demás demandantes y sobre la demandada (CE, Tercera, 1 ago. 2012, D. Rojas, Rad.: 30388).

Esta causal tampoco tiene un mayor desarrollo en los autos que profieren el Consejo de Estado y el Tribunal Administrativo de Cundinamarca. Los magistrados se limitan a establecer que la esfera de disposición del derecho de la persona es más reducida que aquella que comprometió en la conciliación.

\section{Causales de improbación propias de la conciliación judicial}

\section{a) La entidad incurre en abuso del derecho en el acuerdo conciliatorio}

El Consejo de Estado mediante auto de abril del 2014 unificó su jurisprudencia en relación con los mínimos por los que se pueden conciliar los derechos de una víctima, de manera que se pueda afirmar que la conciliación es justa y la entidad no incurre en un abuso del derecho. A continuación se explicarán los fundamentos de este auto con el fin de entender plenamente esta causal de improbación. Sin embargo, es importante resaltar que en noviembre del 2014 el Consejo de Estado modificó su jurisprudencia de forma tal que, hoy por hoy, esta causal ya no es aplicable. Este último fallo también será desarrollado para permitir que la posición actual del Consejo de Estado quede comprendida.

i. Auto de abril del 2014

En este el Consejo de Estado comienza por reconocer que la posibilidad de suscribir conciliaciones materializa el principio de la autonomía de la voluntad de las partes y de manera literal establece:

Dentro de esta noción tradicional, las ideas de justicia y equilibrio contractual se garantizan con fundamento en el ejercicio de la libertad y la no intervención del Estado, de manera que el contrato o el acuerdo, desde su inicio, siempre es justo y equilibrado, puesto que su contenido es el resultado de la libre manifestación de voluntad de los propios contratantes (CE, Tercera, 28 abr. 2014, Rad.: 41834). 
Sin embargo, establece también que la autonomía de la voluntad no es ilimitada, y que encuentra un claro límite en el abuso de la posición de dominio de la persona dominante en la relación inter partes:

En el Derecho Colombiano existe una clara tendencia a proscribir y limitar los acuerdos que contengan cláusulas abusivas, vejatorias, leoninas, esto es aquellas que muestren de manera evidente, injustificada e irrazonable una total asimetría entre los derechos, prestaciones, deberes y/o poderes de los intervinientes, en especial cuando uno de ellos sea el mismo Estado, todo lo cual, debe enfatizarse, encuentra amplio y suficiente fundamento constitucional, partiendo del preámbulo de la Carta Política (CE, Tercera, 28 abr. 2014, Rad.: 41834).

En esta medida, establece el Consejo de Estado, Ias conciliaciones suscritas por la entidad deben estructurarse partiendo de la igualdad entre las partes, lo que implica no abusar de la posición dominante que tiene la entidad en atropello de las víctimas.

Surge así, en cabeza del juez administrativo, la obligación de verificar que el acuerdo conciliatorio no implique un claro detrimento de los derechos de los particulares. La pregunta es, entonces: ¿cuáles son los parámetros para establecer que un acuerdo es abusivo de los derechos de los particulares y por ende contrario a derecho? El Consejo de Estado ha establecido los siguientes criterios:

i) Cuando exista sentencia condenatoria de primera instancia y el acuerdo tenga como objeto un porcentaje de esa indemnización, la conciliación podrá convenirse entre el $70 \%$ y el $100 \%$ de esa condena.

ii) Cuando la sentencia de primera instancia no hubiere sido estimatoria de las pretensiones o ésta aún no se hubiere proferido, el monto del acuerdo conciliatorio podría acordarse entre el $70 \%$ y el $100 \%$ de las sumas que esta Corporación, también de forma indicativa, ha señalado como plausibles para el reconocimiento de las indemnizaciones a que puede haber lugar según el perjuicio de que se trate en razón de la situación fáctica y la intensidad y prolongación del daño -entre otros factores-, según corresponda (CE, Tercera, 28 abr. 2014, Rad.: 41834).

Conviene precisar que estos parámetros no deben aplicarse en aquellos eventos en los cuales, aunque se encuentre acreditado el daño, no suceda lo mismo con el quantum del perjuicio. En estos casos el propio juez debería acudir a la "equidad" para determinar el monto de la indemnización.

ii. Auto de noviembre del 2014

Este auto de unificación de forma explícita busca dejar sin efectos los límites establecidos por el auto de abril del 2014, antes explicado.

Comienza por hacer referencia a la manifestación de la voluntad como fuerza normativa. Explica que esta fuerza surge del hecho de que es inherente a la naturaleza humana buscar el propio beneficio. Es por esto que resulta lógico que en ejercicio de la autonomía de la voluntad, las personas otorguen su consentimiento solo cuando les resulta beneficioso alcanzar una me- 
jora en sus condiciones de vida (CE, Tercera, 24 nov. 2014, E. Gil, Rad.: 37747). Textualmente el Consejo de Estado establece:

Siendo así, está casi totalmente garantizado que las normas jurídicas creadas por y para las personas que conforman un negocio específico, están revestidas de la justicia suficiente para que las mismas hayan decidido vincularse jurídicamente, pues, si el efecto fuera adverso a las partes, no lo hubieran hecho. Por lo tanto, el ejercicio de la autonomía de la voluntad lleva implícito el precepto de justicia que busca cada persona al someterse a una relación jurídica (CE, Tercera, 24 nov. 2014, E. Gil. Rad.: 37747).

Continúa el Consejo de Estado afirmando que la conciliación es una de las manifestaciones más claras de la fuerza vinculante del acuerdo de voluntades. En el caso particular de la conciliación administrativa los límites que se imponen son más estrictos que aquellos de la conciliación entre privados. Lo anterior, en la medida en que la conciliación administrativa debe reflejar los fines esenciales del Estado social de derecho. Para esto, afirma el Consejo de Estado, el ordenamiento jurídico les otorga a los particulares tres garantías:

La primera es el requisito indispensable de que ambas partes se encuentren representadas por abogados de manera que exista plena certeza de que entienden el contenido de la conciliación y su trámite.

La segunda garantía es la cualificación del sujeto conciliador, en cabeza del Ministerio Público. El objeto específico de la intervención de la Pro- curaduría es velar por el cumplimiento del ordenamiento jurídico, la protección del patrimonio público y la garantía de los derechos fundamentales.

Finalmente, la tercera garantía consiste en la verificación que debe hacer el juez administrativo sobre la legalidad del acuerdo al que hayan llegado las partes.

Dadas estas garantías, el Consejo de Estado considera que la conciliación en materia administrativa garantiza la igualdad entre las partes. A partir de este postulado, establece que no hay motivo alguno para considerar que existe una posición de dominio del Estado frente al particular, que justifique que jurisprudencialmente se limite la libertad negocial de las partes.

Literalmente, la sentencia concluye frente a este punto:

De esta manera, la restricción que hizo la Sala, de aprobar los acuerdos solo si se concilia entre el 70 y el $100 \%$ de la condena de primera instancia, afecta la autonomía de la voluntad privada y la capacidad negocial de las partes. Pues, si ambos interesados se ponen de acuerdo en una cifra inferior, como se viene de explicar, esta decisión obedecerá a la voluntad libre y espontánea del ciudadano y de la entidad estatal, quienes -por lógica- habrán actuado de acuerdo a la persecución de sus intereses y su bienestar, teniendo en cuenta que si lo aprobaron, es porque previamente existió negociación en el sentido de definir el monto de la obligación, la forma de pago, el plazo, etc. Y que ambas partes conservaron hasta el final la facultad de conciliar o no. 
En consecuencia, procede la Sala a modificar y unificar la jurisprudencia en este sentido, en tanto excede sus facultades fijar límites objetivos o raseros a los acuerdos conciliatorios, y en aras de respetar y hacer prevalecer la autonomía de la voluntad privada, suprimirá los topes previamente establecidos como requisito para aprobar la conciliación (CE, Tercera, 24 nov. 2014, E. Gil, Rad.: 37747).

Este cambio jurisprudencial es beneficioso en la medida en que frente a los límites que antes imponía el Consejo de Estado existen una serie de importantes críticas y efectos nocivos que podrían redundar en la promoción de la conciliación como mecanismo alternativo de solución de conflictos, rentable para ambas partes.

Lo primero que hay que precisar es que no existe en el ordenamiento colombiano una disposición legal que limite el monto por el cual las partes pueden suscribir la conciliación. Esto encuentra su sustento precisamente en la naturaleza misma de este mecanismo de resolución, que es autocompositiva.

El ordenamiento jurídico potencializa la autonomía de las personas permitiéndoles resolver los conflictos que los involucran en la forma que lo consideren conveniente, dadas distintas variables como por ejemplo: sus posibilidades de ganar un litigio, el tiempo de duración que tendría el litigio, sus necesidades inmediatas de dinero, entre otras. No hay que perder de vista que los particulares, aun habiendo ganado el litigio en primera instancia, no tienen una certeza del $100 \%$ en cuanto a la favorabilidad del fallo para sus pretensiones.
Ahora, para el caso particular de la conciliación en materia administrativa, el legislador previó que los jueces administrativos deben aprobar las conciliaciones que suscriban las entidades con la finalidad de verificar que no se le ocasione un detrimento al patrimonio público de todos los colombianos. Sin embargo, el legislador no les otorgó esta facultad a los jueces respecto del patrimonio de los particulares. Haberlo hecho hubiese implicado una restricción de carácter paternalista que, de acuerdo con una multiplicidad de pronunciamientos de la Corte Constitucional, no están permitidas en un Estado social de derecho, salvo que la medida sea sometida a un test estricto de proporcionalidad.

Pues bien, en este caso el tribunal de cierre de lo contencioso administrativo se atribuyó la facultad de restringir la autonomía de los particulares sin la suficiente carga argumentativa, propia del test de proporcionalidad, que sirviera para justificar la constitucionalidad de esta medida paternalista.

En adición a estos argumentos de naturaleza jurídica, existen también argumentos de tipo práctico.

Limitar la posibilidad de las entidades para conciliar por un mínimo del $70 \%$ contribuye a desincentivar el uso de la conciliación, por cuanto ya no resultaría económicamente conveniente suscribirla. Lo anterior, pues el promedio de duración del proceso revisado por el Consejo de Estado es de doce años, durante los cuales la entidad podría obtener un mayor ahorro invirtiendo los recursos que son objeto de litigio. 
Si por ejemplo, la entidad es demandada por 70 millones de pesos, puede tomar la decisión de conciliar por el 70\%, es decir, 49 millones de pesos, y se ahorrará 21 millones de pesos.

Sin embargo, si por ejemplo invierte estos recursos en un certificado de depósito a término (CDT), en diez años esos 70 millones de pesos tendrán un valor aproximado de 114 millones de pesos, es decir, los rendimientos serán de 44 millones de pesos. En esta medida, si al cabo de los diez años el Consejo de Estado condena a la entidad al pago de la totalidad de los 70 millones de pesos, la entidad igual habrá obtenido mayores ingresos que conciliando en un primer momento por los 49 millones de pesos.

Estos argumentos Ilevan a concluir que el cambio jurisprudencial resultó beneficioso tanto para las entidades del Estado como para los particulares interesados en ponerle fin a sus conflictos con el Estado a través de la conciliación.

\section{b) Fallo extra petita en la sentencia de primera instancia}

Una sentencia extra petita ocurre cuando el juez que conoce del caso le otorga a la parte ganadora del litigio más pretensiones de las que esta solicitó en su demanda.

El Consejo de Estado ha establecido en sus autos improbatorios, que cuando el juez de primera instancia falla extra petita a favor del particular y las partes luego formulan su conciliación de acuerdo con lo establecido en este fallo, se puede incurrir en un detrimento injustificado del patrimonio público. Por esta razón, esta Alta
Corte no aprueba este tipo de conciliaciones y sugiere que la legalidad o ilegalidad del fallo se debe determinar en el curso del proceso.

Un ejemplo de esta circunstancia se encuentra en el auto del 23 de mayo del 2012. En los antecedentes de este caso ocurre que uno de los demandantes solicitó por daño a la vida en relación la suma de 80 salarios mínimos mensuales vigentes. El juez falló en contra de la Fiscalía General de la Nación (entidad demandada) por privación injusta de la libertad y la condenó a pagar, a favor del demandante, un total de cien salarios mínimos mensuales por daño a la vida en relación. Posteriormente, en el acuerdo conciliatorio al que llegan las partes, estas acuerdan que la Fiscalía les pagaría a los demandantes el $60 \%$ de lo concedido en la sentencia de primera instancia.

Ante esta circunstancia el Consejo de Estado afirma:

No es procedente aprobar el acuerdo conciliatorio al que llegaron las partes, toda vez que el hecho de haber fallado el Tribunal Administrativo del Valle del Cauca de manera extra petita puede resultar lesivo del patrimonio público y, por consiguiente, violatorio del principio de legalidad, pero este es un análisis que esta Corporación no puede hacer en esta oportunidad procesal, pues debe ser el resultado propio del curso de la acción, es decir, debe efectuarse en la sentencia (CE, Tercera, 23 may. 2012, C. Zambrano, Rad.: 38146).

En este caso tenía sentido que el Consejo de Estado improbara el acuerdo pues la conciliación se estructuró a partir de un fallo que muy 
posiblemente estaba viciado por una vía de hecho. En esta medida, tiene sentido y puede resultar más beneficioso para el Estado esperar a que se profiera una sentencia en segunda instancia que corrija esta circunstancia. Sin embargo, hubiera sido también recomendable que las partes presentaran un segundo acuerdo conciliatorio en el que omitieran pactar sobre los daños a la vida en relación del demandante, pero que les permitiera reducir el monto de la condena en contra de la entidad por los demás perjuicios.

\section{c) El acuerdo no versa sobre derechos económicos}

El Consejo de Estado ha establecido reiteradamente que para que pueda proceder la conciliación en temas administrativos es un requisito indispensable que el acuerdo verse sobre acciones o derechos económicos disponibles por las partes. Esto reafirma lo dispuesto en el artículo 59 de la Ley 23 de 1991 y el artículo 70 de la Ley 446 de 1998.

Por tanto, es necesario que todas las cláusulas en el pacto tengan implícitas las obligaciones de dar, hacer o no hacer con un contenido económico.

Una circunstancia que ejemplifica esta causal se encuentra en el auto del Tribunal Administrativo de Cundinamarca del 23 de noviembre de 2010, en que cita las normas que ya se mencionaron para afirmar que un acuerdo conciliatorio en torno a una controversia contractual no puede ser aprobado si alguna de sus cláusulas no hace referencia a temas económicos. En conse- cuencia, imprueba el acuerdo por tener cláusulas del siguiente orden:

i. Ampliación del plazo total del contrato en 320 días de ejecución.

ii. Definición del cronograma de actividades a desarrollar en los 320 días adicionales de ejecución.

iii. Definición de los pesos porcentuales de los subsistemas en el precio del contrato

iv. Acuerdo sobre la forma de pago de las obligaciones del contrato.

A pesar de que estas cláusulas implican obligaciones en cabeza de cada una de las partes, no se puede afirmar que estas sean cuantificables monetariamente. En este sentido el Tribunal se acoge a lo establecido por la ley e imprueba la totalidad del acuerdo.

\section{d) Falta de representación}

Uno de los requisitos que establece la Ley 640 de 2001 en el art. 1 para la aprobación de una conciliación, es que las partes se encuentren debidamente representadas y que sus representantes cuenten con la facultad de conciliar.

En cuanto a la indebida representación, el Consejo de Estado ha citado en el auto de 4 de diciembre de 2013 doctrina que establece:

Es de resaltar que la causal de nulidad también opera cuando el apoderado carece totalmente de poder para actuar, dado que en aquellos casos la vulneración del derecho de defensa se hace evidente (...), esto en tanto, la voluntad 
del sujeto para actuar en el proceso a través de un abogado es inexistente (Prieto, 2000, pág. 333).

Esto significa que cualquier conciliación suscrita por un abogado que carezca completamente de poder para representar a la parte o cuyo poder no implica la facultad específica para conciliar, debe ser improbada por el juez contencioso por violar el debido proceso de la víctima.

Esta circunstancia se puede ver en el auto del 4 de diciembre del 2013, en donde el Consejo de Estado imprueba la conciliación, pues el abogado que la suscribió comprometió los derechos de una víctima que previamente había manifestado no tener interés alguno en conciliar:

Resulta necesario precisar que existe también una indebida representación, por ausencia del ius postulandi, cuando quien actúa en representación aparente de los derechos del mandante o del sujeto pasivo, le ha sido revocado el poder por cualquiera de los extremos procesales (...) en ausencia del elemento esencial del contrato de mandato. Una valoración en sentido opuesto, transgrediría el debido proceso, en particular el derecho a la defensa (CE, Tercera, 4 dic. 2013, E. Gil, Rad.: 4265).

Se puede ver entonces cómo el Consejo de Estado ha asociado el derecho de las víctimas al debido proceso de manera directa con el hecho que el poder del abogado sea otorgado en forma correcta, especificando la facultad que este tenga de conciliar y que siga vigente al momento en el que se suscriba la conciliación.

\section{e) Conciliación sobre derechos de menores} de edad

Otra modalidad en la que el Consejo de Estado también ha establecido que el acuerdo conciliatorio resulta evidentemente desproporcionado o abusivo contra los intereses de los particulares, es cuando se pactan derechos de los menores de edad. Lo anterior, aun si los mismos representantes del menor han autorizado de manera libre su interés por conciliar los derechos de los niños.

En sentencia del 6 de febrero de 2012 el Consejo de Estado estableció que los derechos de los menores de edad son prevalentes e irrenunciables, por lo que improbó el acuerdo conciliatorio en el que la madre de una menor acordó que el Ministerio de Defensa le debería pagar el 50\% de la condena proferida por el juez administrativo de primera instancia, en relación con los daños que se le causaron.

En dicha oportunidad la Sala expresó:

El despacho improbará el acuerdo logrado entre las partes, por considerar que se está frente a una menor de 11 años, quien al momento de interponer la demanda tenía tan solo 5 y perdió a su padre dos años antes, de manera que, se harán prevalecer sus derechos sobre los demás demandantes e incluso sobre los de la entidad demandada (CE, Tercera, 6 feb. 2012, S. Conto, Rad.: 38896).

Ahora, no existe claridad en cuanto a si el Consejo de Estado considera prohibido que se concilie sobre derechos de los menores, aun con la autorización de los padres, o si en este caso es 
el porcentaje de la conciliación lo que se considera inapropiado.

\section{f) Desconocimiento de la jurisprudencia sobre perjuicios inmateriales}

Esta causal consiste en que la conciliación es improbada dentro del proceso, cuando la sentencia de primera instancia, conforme a la cual se estructura la conciliación, desconoce la jurisprudencia del Consejo de Estado que ha determinado las distintas categorías sobre perjuicios inmateriales. En esta medida, la sentencia de primera instancia crea nuevas categorías de daños inmateriales que le causan un detrimento patrimonial injustificado al Estado.

La jurisprudencia del Consejo de Estado en relación con los perjuicios inmateriales ha sido extensa y muy diversa en cuanto a las distintas categorías de este tipo de daños que se les deben reconocer a los particulares.

Por no ser el objeto de este trabajo, no se hará un recuento histórico de la evolución que esta jurisprudencia ha tenido. Sin embargo, sí vale la pena establecer qué han determinado los últimos pronunciamientos de esta Corte en cuanto a los perjuicios inmateriales y sus respectivos límites.

Para el reconocimiento de perjuicios morales se establecen cinco niveles de cercanía afectiva entre la víctima o causante y quienes reclaman perjuicios, así:

Nivel 1, entre cónyuges o compañeros permanentes o relación padres e hijos (primer grado de consanguinidad), demostrada mediante prueba del estado civil o de la convivencia de los compañeros. A ellos se les entregará máximo 100 sMLMv como indemnización.

Nivel 2, entre hermanos, abuelos y nietos (segundo grado de consanguinidad). A ellos se les entregará hasta 50 smLmv como indemnización.

Nivel 3, tercer grado de consanguinidad, y debe ser demostrada la relación afectiva. A ellos se les entregará hasta 35 sMLMV como indemnización.

Nivel 4, cuarto grado de consanguinidad o civil, y debe ser demostrada la relación afectiva. A ellos se les entregará hasta 25 smLmv como indemnización.

Nivel 5, comprende las relaciones afectivas no familiares (terceros damnificados), y debe ser demostrada. A ellos se les entregará hasta 15 SMLMV como indemnización.

Cuando se presenta una privación injusta de la libertad, se tendrán en cuenta los niveles señalados anteriormente para fijar la cercanía afectiva, y se establecen los siguientes montos, según el periodo que duró retenida la víctima:

Cuando la retención es mayor a 18 meses, se otorgarán hasta 100 smLmv para el primer grado de consanguinidad; hasta 50 para el segundo grado de consanguinidad; hasta 35 para el tercer grado de consanguinidad; hasta 25 para el cuarto grado de consanguinidad; y hasta 15 para los terceros damnificados.

Si la retención está entre 12 y 18 meses, se otorgarán 90, 45, 31.5, 22.5 y 13.5 SMLMv, para pri- 
mer, segundo, tercer y cuarto grado de consanguinidad y terceros damnificados, respectivamente.

Cuando la retención es superior a 9 meses e inferior a 12 meses, los topes de indemnización serán de 80, 40, 28, 20 y 12 smLmv, para primer, segundo, tercer y cuarto grado de consanguinidad y terceros damnificados, respectivamente.

Si la retención es superior a 6 meses e inferior a 9 , se otorgarán hasta $70,35,24.5,17.5,12.5$ y 7.5 SMLMv, para primer, segundo, tercer y cuarto grado de consanguinidad y terceros damnificados, respectivamente.

Si la retención está entre 3 y 6 meses, se podrán entregar hasta 50, 25, 17.5, 12.5 y 7.5 sMLMV, para primer, segundo, tercer y cuarto grado de consanguinidad y terceros damnificados, respectivamente.

Cuando la retención es superior a 1 mes, pero inferior a 3 meses, los topes de indemnización serán de 35, 17.5, 12.25, 8.75 y 5.25 smLmv, para primer, segundo, tercer y cuarto grado de consanguinidad y terceros damnificados, respectivamente.

Finalmente, si la privación injusta de la libertad fue de menos de un (1) mes, los topes de indemnización serán de 15, 7.5, 5.25, 3.75 y 2.25 , para primer, segundo, tercer y cuarto grado de consanguinidad y terceros damnificados, respectivamente.

Así mismo, la Sala establece que para que proceda el reconocimiento de los perjuicios materiales en la modalidad de lucro cesante, se re- quiere que se acredite que la víctima de la privación injusta, al momento de la detención, se encontraba en edad productiva y, por lo menos, se tendrá en cuenta un salario mínimo, más el $25 \%$ por concepto de prestaciones sociales.

En los casos de daño a la salud, la Sala establece que no se puede limitar el daño a la salud al porcentaje certificado de incapacidad, sino que se deben considerar las consecuencias de la enfermedad o accidente que reflejen alteraciones al nivel del comportamiento y desempeño de la persona dentro de su entorno social y cultural que agraven la condición de la víctima, como por ejemplo los casos estéticos o lesiones a la función sexual, que difícilmente se consideran constitutivos de incapacidad.

La Sala abandona definitivamente la tesis de que solo se ha de indemnizar lo que constituya una alteración grave de las condiciones de existencia, y acoge jurisprudencia sobre la conveniencia de aplicar medidas de reparación integral en los casos en los que se echa de menos el trato que la mujer requiere por su propia condición, lo que evidencia la discriminación de género.

Así las cosas, recuerda que la indemnización está sujeta a lo probado única y exclusivamente para la víctima directa, en un monto que no podrá exceder de 100 smLMv cuando la gravedad de la lesión sea igual o superior al $50 \%$, y que este monto va disminuyendo en la medida en que la lesión sea menor, así: entre $40 \%$ y $50 \%$ de lesión, 80 smLmv; entre $30 \%$ y $40 \%$ de lesión, 60 SMLMV; entre $20 \%$ y $30 \%, 40$ sMLMV, entre 
$10 \%$ y $20 \%, 20$ sMLMV; y, entre $1 \%$ y $10 \%, 10$ SMLMv. En casos excepcionales, esto es, cuando existan circunstancias debidamente probadas de una mayor intensidad y gravedad del daño a la salud podrá otorgarse una indemnización mayor que no podrá superar los 400 smLmv.

Con respecto al lucro cesante consolidado, la nueva línea señala que este corresponde al tiempo transcurrido desde la ocurrencia del daño hasta la fecha de la sentencia, y para establecer el lucro cesante futuro se tiene en cuenta la expectativa de vida del lesionado, de conformidad con la Resolución 0497 de 1997, menos el tiempo reconocido en el lucro cesante consolidado.

Otro de los aspectos abordados por la Sala Plena de la Sección Tercera es la afectación o vulneración relevante de bienes o derechos convencional y constitucionalmente amparados. En caso de violaciones relevantes de este tipo se deben adoptar medidas de reparación integral no pecuniarias a favor de la víctima directa y su núcleo familiar más cercano, de acuerdo con los hechos probados. En casos excepcionales, cuando no sea suficiente la reparación con medidas no pecuniarias, se otorgará hasta 100 SMLMv, proporcional al daño, siempre que no se trate del derecho a la salud.

Cualquier categoría distinta que reconozca un tribunal de inferior jerarquía, implica una vía de hecho y por ende la imposición de una erogación injustificada de recursos públicos.

Un ejemplo de esta circunstancia se encuentra en el auto del 18 de noviembre de 2010 proferi- do por el Consejo de Estado, en donde esta Alta Corte establece:

En efecto, según el consenso al que arribaron las partes, la entidad demandada reconocerá el $85 \%$ de la condena de primera instancia lo cual, prima facie, daría lugar a la aprobación del acuerdo; no obstante, en la misma se reconocieron a favor del demandante los perjuicios inmateriales que a continuación se transcriben:

Los perjuicios a la vida en relación se pueden discriminar en varios ítems a saber:
a. Daño fisiológico
b. Daño a la vida
c. Daño a la vida de relación social
d. Daño a la vida de relación familiar
e. Daño estético

De allí que se imponga la improbación del acuerdo conciliatorio ya que la condena por concepto de perjuicios inmateriales, en la forma como fue liquidada por el Tribunal de primera instancia puede resultar lesiva para el patrimonio público.

\section{(...)}

En efecto, esta Corporación ha reconocido la posibilidad de indemnizar los rubros denominados daño a la vida en relación, bajo una tipología abierta de perjuicios inmateriales, pero resulta evidente que la segregación desarrollada por el a quo desborda en amplio margen los lineamientos trazados por la jurisprudencia en la materia (CE, Tercera, 18 nov. 2010, E. Gil, Rad.: 38222).

Resulta fundamental entonces que los jueces conozcan las tendencias jurisprudenciales en 
indemnización de perjuicios de manera que no cierren las puertas a conciliaciones que puedan tener lugar en segunda instancia. Esto es especialmente importante cuando hay entidades del Estado involucradas en el litigio.

\section{Causales de improbación propias de las conciliaciones extrajudiciales}

\section{a) No es procedente la conciliación para reclamar el derecho}

La única causal propia de la conciliación extrajudicial consiste en que el Tribunal Administrativo de Cundinamarca, luego de revisadas las pruebas del proceso, considera que ya existe un derecho claro expreso y exigible que no es necesario reclamar mediante conciliación.

Un caso que ejemplifica esta situación se puede ver en el auto proferido por el Tribunal el 28 de noviembre de 2013, en donde el INPEC y un consorcio presentan ante la jurisdicción una conciliación por la cual se pretendía hacer valer unos títulos valores que respaldaban una obligación contractual de la entidad.

Ante esta situación, el pronunciamiento es el siguiente:

La Sala concluye que se encuentra soportada la suma convenida en la conciliación.

No obstante, considera que las pruebas aportadas dentro del acuerdo conciliatorio, resultan no ser relevantes en el presente estudio dado que no se entran a evaluar, ya que en tratándose de títulos ejecutivos, como en el presente caso, dicho estudio queda de lado. En conse- cuencia, el presente acuerdo conciliatorio no puede ser aprobado, pues se concilia sobre un monto que debe ser reclamado a través de un proceso ejecutivo (CE, Tercera, 28 abr. 2014, M. Fajardo, Rad.: 46482).

Así, se considera acertado improbar el acuerdo conciliatorio, pues el propósito principal de la conciliación es precisamente constituir un título que establezca obligaciones claras, expresas y exigibles en cabeza de cada una de las partes. De presentarse el incumplimiento de las obligaciones de alguna de las partes, la otra puede acudir ante la jurisdicción para reclamar sus derechos en un proceso ejecutivo. En este caso, si ya existía un título ejecutivo que contenía todas las obligaciones de las partes, estaba de más intentar reclamarlas a través de una conciliación.

\section{RECOMENDACIONES}

\section{A. Recomendaciones para la gestión de las entidades}

A partir del análisis de las causales por las que se imprueban las conciliaciones y de la frecuencia con que estas se presentan, es posible formular algunas recomendaciones que las entidades deberían tener en cuenta antes de presentar ante la jurisdicción administrativa los acuerdos conciliatorios que suscriban con los particulares.

1. El primer aspecto que las entidades deben verificar antes de presentar la solicitud de conciliación ante los jueces administrativos, es que tanto la existencia del daño, como su 
cuantía, y la legitimidad de la víctima para reclamar la indemnización, se encuentren probados.

Esto implica comprobar que exista una justificación razonable para cada una las sumas que se concilian con los particulares, así como que efectivamente la persona que reclama los perjuicios tenga legitimidad para hacerlo.

Para esto, la entidad debe cerciorarse de que los hechos que requieran de ciertas formalidades probatorias efectivamente las cumplan. Así por ejemplo, tratándose de la propiedad de bienes inmuebles no basta con tener la promesa del contrato de compraventa o el certificado de tradición, sino que por ley se ha establecido que es necesario aportar la escritura pública (D. 1250/1970, art. $2^{\circ}$ ). Otro ejemplo es el de la prueba de la filiación de los hijos a sus padres, para lo que necesariamente se debe aportar el registro civil de nacimiento de los hijos (L. 75/1968, art. $1^{\circ}$ ).

Estas formalidades probatorias pueden resultar especialmente importantes para verificar la propiedad de un bien frente al cual se reclama la indemnización de daños, y para determinar quiénes tienen legitimidad en la causa para solicitar la indemnización de prejuicios materiales y morales.

Es recomendable hacer esta verificación en cuanto a las pruebas, independientemente de que ya exista una sentencia en primera instancia. Como se pudo ver, en muchos ca- sos en las improbaciones por falta de pruebas ya existía una sentencia previa de primera instancia.

2. Cuando la causal de improbación sea la falta de pruebas y no exista claridad en cuanto a qué aspectos fue insuficiente el material probatorio, es recomendable que la entidad, durante el término de ejecutoria del auto, solicite una adición en donde se le pida al Juez especificar las razones por las que se imprueba el auto, de acuerdo con lo establecido en los artículos 311 del Código de Procedimiento Civil y 287 del Código General del Proceso.

3. Es también importante que en caso de haber una sentencia de primera instancia, la entidad compare aquello que en un principio solicitó el demandante en sus pretensiones con lo que le otorgó el juez. Esto permitirá constatar si pudo haber un fallo extra petita, esto es, una sentencia en donde el juez haya otorgado más de lo que el demandante pretendía.

De ser este el caso, la recomendación es no conciliar sobre este punto y, por el contrario, interponer los recursos necesarios para que se corrija la sentencia.

4. Las entidades deben verificar que no haya operado ni la prescripción, ni la caducidad de la acción. Esto exige no solamente tener claros los términos que tienen los particulares para iniciar las distintas acciones en contra del Estado, sino también tener claridad en cuanto a la jurisprudencia y la normatividad que existe sobre la interrupción y suspensión 
de la prescripción y de la caducidad en distintas ocasiones. Vale la pena entonces comprobar si se interrumpió o no la prescripción, y por cuánto tiempo, por ejemplo: i. cuando se retira la demanda, ii. cuando esta es rechazada por el juez, iii. cuando el arbitramento no se puede llevar a cabo, entre otras cosas, por vacíos en las cláusulas compromisorias o por la imposibilidad de conformar el tribunal.

5. Las entidades deben revisar si todas las personas que reclaman la indemnización de daños tienen legitimidad por pasiva para ser parte en todo o en parte de la conciliación. Entonces, es necesario verificar que las personas que afirman haber sufrido perjuicios materiales e inmateriales los hayan efectivamente padecido, dadas las circunstancias de tiempo, modo y lugar en las que ocurrió el daño.

Por ejemplo, si una persona que no había nacido al momento de ocurrirle el daño a la víctima, reclama la indemnización de perjuicios morales o de daño a la vida en relación, es necesario tener especial cuidado al cerciorarse de que efectivamente esta haya sufrido el perjuicio y que esto esté probado en el proceso.

6. Es importante que las entidades tengan certeza de cuáles son los derechos que le pertenecen a cada una de las víctimas, para que de forma organizada se pueda conocer qué personas deben suscribir la conciliación y hasta qué punto pueden tomar decisiones en cuanto a los derechos conciliados.
7. Si se pretende conciliar derechos de un mayor de edad que al momento de ocurrir los hechos era un niño, es recomendable que esta persona suscriba un nuevo poder en donde de forma clara exprese que en su nueva calidad de mayor de edad está de acuerdo con conciliar sus derechos. Este, sin embargo, no es un requisito indispensable pues el Consejo de Estado ha reiterado que no es necesario que los adultos que hayan iniciado el proceso siendo niños vuelvan a otorgar un nuevo poder al cumplir la mayoría de edad.

8. Otro aspecto que las entidades deben tener en cuenta, es que no exista un título ejecutivo que ya consagre aquellos aspectos que se plasman en la conciliación. Sí ya existen garantías a favor de la entidad, no es necesario aprobarlas por medio de la conciliación. Basta con iniciar un proceso ejecutivo para su cobro.

9. Antes de presentar la conciliación ante el juez administrativo, vale la pena revisar cada una de las cláusulas de la conciliación para tener la certeza de que cada una de estas tiene un contenido que se puede cuantificar en términos económicos. En este sentido, se debe evitar poner cláusulas que sean meras descripciones de obligaciones de hacer, no hacer, o dar, que no se puedan traducir en términos monetarios. Así por ejemplo, no se deben incluir cláusulas que establezcan cronogramas de ejecución, salvo que la definición de estos cronogramas pueda implicar consecuencias económicas, caso en el cual estas consecuencias se deben hacer explícitas. 
10. Las entidades deben hacer una revisión cuidadosa del expediente del proceso que precede a la conciliación, para verificar que el abogado de la víctima tenga un poder debidamente otorgado (lo que implica la presentación personal), que cuente específicamente con la facultad de conciliar y que no haya sido en ningún momento revocado.

Esta revisión se debe hacer con mayor cuidado cuando se trata de los derechos de niños que estén involucrados en la conciliación.

11. Antes de suscribir la conciliación, es importante verificar las líneas jurisprudenciales para determinar cuál ha sido la tendencia del Consejo de Estado en el asunto a conciliar. Esto permite una mayor claridad en cuanto a las posibilidades que tiene la entidad de ganar el caso en un eventual litigio, así como de establecer si se estaría incurriendo en una ilegalidad al aprobar los términos de la conciliación.

Así por ejemplo, si se presenta en la entidad un caso que puede en principio tener las características de un enriquecimiento sin justa causa a favor del particular, es necesario verificar la línea jurisprudencial que sobre esta materia existe (Agencia Jurídica del Estado, 2013), para comprobar si se cumple con todas las características que se requieren para justificar la erogación de recursos públicos para compensar al particular.

12. Finalmente, es recomendable que la entidad no se abstenga de presentar de nuevo la solicitud de conciliación cuando esta ha sido improbada por errores en alguna de sus cláusulas. No hay que perder de vista que si bien al juez no le es posible hacer aprobaciones parciales, sí es posible que las partes concilien parcialmente sobre las pretensiones del litigio, tal y como lo ha establecido el Consejo de Estado:

Conviene agregar que las decisiones adoptadas por esta Subsección han versado respecto de un solo litigio, con una única parte demandante y demandada, en el cual el proceso ha continuado: i) entre la entidad pública accionada y el llamado en garantía, caso en el cual cualquier análisis en torno a la responsabilidad del Estado resulta inane, puesto que el litigio se reduce al análisis de la relación jurídico-sustancial existente entre esas dos personas; ii) entre la parte actora y la parte demandada, cuando el litigio ha sido conciliado en forma parcial, esto es porque sólo el acuerdo conciliatorio versó respecto de algunas - no todas- de las pretensiones o simplemente la conciliación no involucró a la totalidad de los demandantes, evento en el cual el proceso ha de continuar con los demás actores. ${ }^{1}$

13. Es también relevante que las entidades conserven en sus archivos copia de los autos inadmisorios, de manera que puedan tener un registro de las causales más comunes por las que la jurisdicción administrativa imprueba las solicitudes de conciliación que se presentan, y hacer conciencia de las falencias en las que incurren con el fin de corregirlas.

Consejo de Estado. Sala de lo Contencioso Administrativo. Sección Tercera. Sentencias de 12 de mayo de 2011, expediente 20.960; 8 de junio de 2011, expediente 18.676; 23 de junio 2011, expediente 19.097; y 8 de febrero de 2012, expediente 21.525. 
14. Por último, es importante que las entidades verifiquen tanto en las conciliaciones judiciales como en las extrajudiciales, que la conciliación respecto de los perjuicios inmateriales se limite a aquellas categorías que jurisprudencialmente el Consejo de Estado ha determinado. Si se pactan nuevas cuantías que le representen al Estado un detrimento patrimonial, se entenderá que el acuerdo es lesivo para el patrimonio.

\section{B. Recomendaciones para los jueces administrativos}

De los hallazgos de este estudio se derivan las siguientes recomendaciones para los jueces administrativos, que pueden contribuir en la disminución del número de conciliaciones que se imprueban:

1. En cuanto a la manera en la que los jueces se aproximan a la conciliación, lo primero que es necesario resaltar es la importancia de que exista una mayor transparencia sobre las razones por las que se imprueban las conciliaciones. Específicamente, en los casos relacionados con la falta de suficiente material probatorio, los jueces tienden a ser genéricos en su motivación. Esto es, afirman que no existe suficiente material probatorio pero no especifican qué aspecto de la responsabilidad no estuvo suficientemente probado.

Aunque es cierto que los jueces no pueden prejuzgar en los autos que emitan a lo largo del proceso judicial, lo cierto es que se debería encontrar un equilibrio que permita tener certeza sobre la imparcialidad del juez, y a las entidades saber cuáles son las falencias en el material aportado con la solicitud. Esto contribuirá no solo a hacer las debidas correcciones para presentar de nuevo la conciliación, sino a que las entidades puedan mantener un registro que les ayude a corregir errores probatorios recurrentes.

También en relación con las pruebas, es importante recomendar a los jueces administrativos que mantengan la coherencia de sus fallos con los pronunciamientos que se realicen en los autos improbatorios. En el 33\% de los casos en los que el juez falló a favor del particular en la primera instancia del proceso, la conciliación fue improbada por "falta de pruebas" en la segunda instancia del proceso. En estos mismos casos, el fallo definitivo, es decir, el fallo que imparte el mismo juez que improbó la conciliación por falta de pruebas, continúa favoreciendo los intereses del particular. Esto evidencia una falta de coherencia e incluso de imparcialidad en algunos casos.

Ahora, el análisis en cuanto a la suficiencia de las pruebas debe ser especialmente riguroso cuando ya ha existido un fallo en primera instancia a favor de los intereses de los particulares. Lo anterior, pues para el momento en que la conciliación va a ser evaluada por el juez administrativo durante la segunda instancia del proceso, las pruebas ya habrán sido evaluadas por el comité de conciliación de la entidad, por el apoderado de la entidad, por el apoderado de la víctima y por el juez de primera instancia. 
2. Para disminuir los autos improbatorios, los jueces deben tener una mayor proactividad en la corrección de ciertas formalidades procesales que puedan implicar la improbación del acuerdo conciliatorio. En esta investigación se puedo comprobar que esta recomendación resulta especialmente importante en cuanto a las pruebas del proceso y los poderes que otorgan las partes.

Por ejemplo, en el ya mencionado caso del Consejo de Estado del 6 de diciembre de 2010, ${ }^{2}$ esta Alta Corte improbó el acuerdo conciliatorio en razón de que la propiedad de un inmueble se pretendía probar solo con el certificado de libertad y tradición y no con la escritura pública. La improbación de esta conciliación se pudo haber evitado si de oficio la magistrada le hubiese solicitado a las partes aportar la copia de la escritura pública.

Esto mismo ocurre, por ejemplo, en casos en donde la filiación de ciertas víctimas se pretende demostrar mediante un medio probatorio distinto al registro civil de nacimiento. Los jueces podrían decretar la prueba conducente para probar este hecho del proceso sin necesidad de improbar el acuerdo.

Otro aspecto frente al cual los jueces deben ser proactivos para contribuir a disminuir las conciliaciones improbadas tiene relación con las falencias en los poderes que otorgan las partes. Si un poder no expresa claramente la facultad que el apoderado tiene, por ejemplo,

2 Sala de lo Contencioso Administrativo. Sección Tercera. C. P.: Olga Valle de la Hoz. Rad.: 33462. para conciliar los derechos de uno de los involucrados en el proceso, el juez administrativo puede exhortar a las partes para que lo aporten en debida forma, en lugar de improbar la conciliación, de entrada.

3. Es necesario que exista una mayor claridad en cuanto a si los derechos de los menores de edad se pueden conciliar o si por el contrario estos no son de disponibilidad ni siquiera de sus representantes legales.

En el caso que revisa el Consejo de Estado, la conciliación sobre los derechos de los menores es del $50 \%$ de la condena emitida en primera instancia. Frente a esto, dicho órgano se limita a disponer que deben prevalecer los derechos de los menores por lo que imprueba la conciliación. Sin embargo, no establece si la vulneración a los derechos de la niña se ocasiona por el porcentaje sobre el que se pretendía conciliar o si es por el solo hecho de conciliar derechos de un menor.

Es necesario, en relación con este asunto, que los jueces administrativos tengan en consideración que actualmente el promedio de duración de un caso que es estudiado por el Consejo de Estado es de doce años. Esta realidad conlleva que en muchas ocasiones resulte más conveniente para los intereses de los menores conciliar por un porcentaje menor al otorgado en primera instancia, pero con la certeza de tener acceso de forma expedita a los recursos.

Para ilustrar este punto se puede pensar, por ejemplo, en el caso de un menor de tres años 
cuyos padres quieran conciliar sus derechos con el fin de empezar a pagar su educación primaria en el momento en que este cumpla cinco años. Bajo la premisa de que los derechos de los menores no se pueden conciliar, el juez administrativo improbaría la conciliación y forzaría a los padres del menor a esperar en promedio doce años para recibir los recursos. Para este momento el menor de edad tendría quince años y su oportunidad de estudiar la primaria, en concordancia con su edad, ya habrá expirado.

No hay que perder de vista tampoco que aunque las posibilidades de ganar el litigio en segunda instancia son mayores cuando se ha obtenido una sentencia favorable en primera instancia, lo cierto es que nunca hay una certeza del $100 \%$ en cuanto al sentido del fallo en la apelación. Es posible también que al final los particulares, menores de edad incluidos, pierdan el caso y no obtengan ningún tipo de beneficio. Este es otro factor que las partes deben tener en cuenta a la hora de conciliar.

\section{CONCLUSIONES}

El propósito de este estudio era realizar un diagnóstico descriptivo de los autos improbatorios de las conciliaciones presentadas por las entidades del Estado a los jueces administrativos. Su desarrollo permitió entender las principales razones por las que los jueces inadmiten las conciliaciones, así como presentar una serie de recomendaciones que buscan disminuir la posibilidad de que ocurra la improbación.
Algunos de los puntos más importantes que se pudieron constatar en el estudio son los siguientes:

- De las conciliaciones que se improbaban en el curso de una acción de reparación directa, la gran mayoría se relacionaban con casos de privación injusta de la libertad y falla médica.

- De las conciliaciones que se improbaban en el curso de acciones de controversias contractuales, el mayor índice se relacionaba con incumplimiento prestacional en cabeza de la entidad.

- En el $60,5 \%$ de los casos que daban origen a los autos de improbación, ya existía una sentencia previa en primera instancia. En todos estos casos la sentencia favorecía a los particulares.

- Luego de hacer seguimiento a la continuidad de los procesos en el marco de los cuales se improbó la conciliación, se pudo comprobar que en el $40 \%$ de los casos al final la sentencia resulta ser favorable al particular.

- En el $25 \%$ de los casos en los que la sentencia de primera instancia fue desfavorable para el Estado, la segunda instancia resultó favoreciendo sus pretensiones. Esto implica que para la entidad fue benéfico que la conciliación no haya llegado a su fin.

- Las causas por las que se improbó la conciliación durante el periodo 2010-2013, fueron en su orden: falta de suficiente material probatorio que las respalde, el acuerdo puede resultar 
lesivo para el patrimonio público, el acuerdo solo sería aprobado de manera parcial, la caducidad de la acción, la falta de legitimidad por activa, la falta de capacidad para conciliar, se instauró una acción que no era procedente $y$, finalmente, que la víctima no estaba representada por abogado.

- En la mayoría de los casos en los que la conciliación se improbó por falta de pruebas, ni el Consejo de Estado ni el Tribunal Administrativo de Cundinamarca señalaban las razones específicas por las que consideraban que el acervo probatorio no era suficiente.

- En los demás casos en los que se improbaba el acuerdo por falta de pruebas, la razón argumentada por los jueces era que estas no tenían todas las formalidades que exige la ley procesal.

- Los jueces administrativos no aprueban conciliaciones de forma parcial. Si algún punto de la conciliación no se ajusta a derecho, la totalidad de la conciliación debe ser improbada.

- En algunas ocasiones las entidades no tienen claridad en cuanto a los términos de caducidad de la acción, por lo que pretenden suscribir conciliaciones cuando ya ha operado este fenómeno jurídico a favor de la entidad.

- Ocurre también que las entidades no verifican si las personas que reclaman la indemnización de los daños tienen legitimidad por activa, especialmente cuando se trata de casos en los que la respuesta en cuanto a la legitimidad no es obvia. Por ejemplo, cuando un menor que al momento de ocurrir el daño no había nacido, reclama perjuicios inmateriales.

- Las entidades a veces también concilian con personas que no tienen la disponibilidad sobre el derecho que se pretende conciliar. Por ejemplo, cuando el apoderado compromete derechos frente a los cuales el poderdante no ha otorgado autorización alguna.

- Otra causal por la que se imprueban las conciliaciones tiene que ver con el hecho de que las entidades puedan con su conciliación desconocer normas jurídicas que regulan la materia objeto de disputa. Por ejemplo, en el caso del enriquecimiento sin justa causa.

- Sucede también que los jueces administrativos imprueban las conciliaciones cuando estas se estructuran a partir de un fallo extra petita en primera instancia.

- El Consejo de Estado también ha establecido que el acuerdo conciliatorio resulta evidentemente desproporcionado o abusivo contra los intereses de los particulares cuando se pacta sobre derechos de los menores de edad. Sin embargo, no existe certeza sobre si esta prohibición aplica también cuando la conciliación se realiza por encima del $70 \%$ del valor de la sentencia en primera instancia.

- Teniendo en cuenta que los jueces administrativos no aprueban parcialmente conciliaciones, si alguna de las cláusulas del acuerdo no tenía contenido económico (por ejemplo, porque fija 
solamente cronogramas) la improbaban en su totalidad.

- Finalmente, la causal que se presenta con menos frecuencia es la de la falta de representación por parte de un abogado de alguna de las víctimas involucradas en la conciliación

- De estos hallazgos es posible concluir que para contribuir a la disminución de las conciliaciones que imprueban en la rama judicial, es necesario tomar correctivos tanto en la gestión que las entidades hacen de la conciliación como en la manera en que los jueces abordan las solicitudes que se les presentan.

\section{Referencias}

Agencia Jurídica del Estado. (Diciembre, 2013).

Cartilla 7. Responsabilidad patrimonial del Estado fundada en el principio de no enriquecimiento sin justa causa. Obtenido de defensajuridicva: http://www.defensajuridica.gov.co/gestion/publicaciones-andje/Documents/cartilla_n7.pdf

Congreso de la República. (5 de enero de 2011). Ley 640 de 2001. Por la cual se modifican normas relativas a la conciliación y se dictan otras disposiciones.

Consejo de Estado. Sala de los Contencioso Administrativo. Sección Tercera. Rad. 38222 (C. P. Enrique Gil Botero; noviembre 18 de 2010).
Consejo de Estado. Sala de lo Contencioso Administrativo. Sección Tercera. Rad. 33462 (C. P. Olga Valle de la Hoz; diciembre 6 de 2010).

Consejo de Estado. Sala de lo Contencioso Administrativo. Sección Tercera. Rad. 38575 (C. P. Enrique Gil Botero; abril 14 de 2011).

Consejo de Estado. Sala de lo Contencioso Administrativo. Sección Tercera. Rad. 24324 (C. P. Hernán Andrade Rincón; abril 24 de 2012).

Consejo de Estado. Sala de lo Contencioso Administrativo. Sección Tercera. Rad. 31722 (C. P. Mauricio Fajardo Gómez; mayo 23 de 2012).

Consejo de Estado. Sala de lo Contencioso Administrativo. Sección Tercera. Rad. 2001684 (C. P. Hernán Andrade Rincón; julio 5 de 2012).

Consejo de Estado. Sala de lo Contencioso Administrativo. Sección Tercera. Rad. 30388 (C. P. Danilo Rojas Betancourt; agosto 1 de 2012).

Consejo de Estado. Sala de los Contencioso Administrativo. Sección Tercera. Rad. 40588 (C. P. Enrique Gil Botero; noviembre 1 de 2012).

Consejo de Estado. Sala de lo Contencioso Administrativo. Sección Tercera. Rad. 34976 (C. P. Hernán Andrade Rincón; febrero 12 de 2013). 
Consejo de Estado. Sala de lo Contencioso Administrativo. Sección Tercera. Rad. 20060003901 (C. P. Danilo Rojas Betancourt; mayo 29 de 2013).

Consejo de Estado. Sala de lo contencioso Administrativo. Sección Tercera. Rad. 25869 (C. P. Enrique Gil Botero; octubre 24 de 2013).

Consejo de Estado. Sala de lo Contencioso Administrativo. Sección Tercera. (C. P. Enrique Gil Botero; diciembre 4 de 2013).

Consejo de Estado. Sala de lo Contencioso Administrativo. Sección Tercera. Exp. 46486 (C. P. Mauricio Fajardo; enero 29 de 2014).

Consejo de Estado. Sala de lo Contencioso Administrativo. Sección Tercera. Rad. 29273B (C. P. Ricardo Hoyos; julio 25 de 2007).

Consejo de Estado. Sala de lo Contencioso Administrativo. Sección Tercera. Rad. 41834 (C. P. Mauricio Fajardo Gómez; abril 28 de 2014).

Consejo de Estado. Sala de lo Contencioso Administrativo. Sección Tercera. Rad. 41834 (C. P. Mauricio Fajardo Gómez; abril 28 de 2014).
Consejo de Estado. Sala de lo Contencioso Administrativo. Sección Tercera. Rad. 37747 (C. P. Enrique Gil Botero; noviembre 24 de 2014).

Consejo de Estado. Sección Tercera - Subsección B. Exp. 38896 (C. P.: Stella Conto Díaz del Castillo; febrero 6 de 2012).

Prieto, E. (2000). Teoría General del Proceso (Tercera ed.). Bogotá: Temis.

Tribunal Administrativo de Cundinamarca. Sala de lo Contencioso Administrativo. Sección Tercera. Rad. 2011-1425 (M. P. Carlos Alberto Vargas Bautista; abril 11 de 2012).

Tribunal Administrativo de Cundinamarca. Sala de lo Contencioso Administrativo. Sección Tercera. Rad. 2010-862 (M. P. Juan Carlos Garzón Martínez; noviembre 23 de 2010).

Tribunal Administrativo de Cundinamarca. Sala de lo Contencioso Administrativo. Sección Tercera. Rad. 2013-01252 (M. P. Alfonso Sarmiento Castro; noviembre 28 de 2013). 